\title{
Prevalence of Hydatidosis among Slaughtered Sheep in Makkah, Kingdom of Saudi Arabia
}

\author{
Fawzia Hassan Toulah and Ibtehal Mohammad Albalawi* \\ Department of Biology, King Abdulaziz University, Kingdom of Saudi Arabia
}

\begin{abstract}
Hydatidosis is one of the most parasitic diseases transmitted from carnivores (dogs) to human, causing deterioration in health and also transmitted to herbivores animals causing a substantial economic loss in the productivity of meat with low quality. In these days there is an increase in gain dogs at home, with its high risk of infection with many parasitic diseases such as Hydatidosis. The present study was conducted to provide a recent view on the current status of Hydatidosis among slaughter sheep in Makkah through periodic visiting to Alkaakia slaughterhouse three times on week for one year from January 2017 to January 2018. Summer revealed the highest prevalence in sheep. Obtained data about the infection were analyzed statistically was done on the sheep slaughtered there. The total infection rate was $8.12 \%(4284 / 52783)$ in sheep, while the most infected organs were liver.

In conclusion, the high infectivity rate of slaughtered sheep with hydatid cyst revealed to the low health awareness among people, and there is no examination of dogs from parasitic diseases.
\end{abstract}

Keywords: Hydatidosis; Saudi Arabia; Echinococcus

\section{INTRODUCTION}

Parasitic diseases are transmitted from animal to another, and some are transmitted from animal to human or even from human to another. This is another problem in itself, and with the low level of health education in the society and the low of conscious to veterinary services, so these parasitic diseases spread and causing health problems in the world. The most important of these diseases is cystic echinococcosis CE (Hydatidosis) disease, which caused by the larva or adult of Echinococcus spp, belong to the family Taeniidae [1].

Typical live cycle for Echinococcus need two intermediate hosts; adult worm found in the intestine of the carnivores (dogs and foxes) as definitive hosts, while herbivorous (cattle, sheep, and camels) as an intermediate host, where the Metacestode stage (hydatid cyst) develops in their tissues. Humans are infection with Hydatidosis after ingestion the eggs and consider as an accidental intermediate host [2].

Hydatidosis has worldwide spread, especially in the places where there is a contact between the herder and the final host (herbivorous) and highly endemic in North Africa and sub-
Saharan Africa. Also found a high prevalence of CE in Middle East countries, Central Asia, China, India, and Japan. Mediterranean littoral, Southeastern countries Europe record an increase in the ratio of infection, while in the UK and central Europe show low in the infection ratio. Also in Australia report cases of infection since the end of $8^{\text {th }}$ century, and the most cases were in sheep. South America is highly endemic more than North and Central America, while the infection there seems to be rare or not found [3].

From the first studies in Saudi Arabia that care about the distribution of parasitic diseases among slaughtered animals is this research in Al-Qaseem (Bureidah city). They investigated the existance of Metacestode larva among intermediate hosts in the area. The detected the rate of infection with Echinococcus in sheep about $2.13 \%$ [4]. While in north Jeddah, study prevalence between slaughtered animals (91348), including sheep and goats, the highest rate was in sheep at $69.6 \%$, and the most infected organs were the liver [5]. In a study that researches about the epidemiological of the Echinococcus in one year among the animals that slaughtered in Al-Madina Al-Munawwarah.

"Correspondence to: Ibtehal Mohammad Albalawi, Department of Biology, King Abdulaziz University, Kingdom of Saudi Arabia, Tel: +9665444334549; E-mail: Ibtehal.albalawi@hotmail.com

Received: December 13, 2018; Accepted: May 22, 2019; Published: May 29, 2019

Citation: Toulah FH, Albalawi IM (2019) Prevalence of Hydatidosis among Slaughtered Sheep in Makkah, Kingdom of Saudi Arabia. J Bacteriol Parasitol. 10:358.

Copyright: ( 2019 Toulah FH, et al. This is an open-access article distributed under the terms of the Creative Commons Attribution License, which permits unrestricted use, distribution, and reproduction in any medium, provided the original author and source are credited. 
Includes sheep, cattle, camels, and goats, record a low rate of about $2.60 \%$ in sheep [6].

In a recent study among sheep and goats in Taif city, the samples collected randomly from different sources (local or imported). Resulting in that infection ratio in imported sheep and goats higher than a local one [7]. Another study showed the relationship between the rate of infection and the effect of seasons on a one year (2015-2016) among Sawakny sheep, in Riyadh city [8]. The winter was the highest rate of infection at $1.38 \%$, while the summer was the lowest rate of infection at $0.67 \%$. Also, study the prevalence of cyst on organs, as it is expecting the liver takes the high ratio in infection $79.1 \%$, and the lung comes after it in the most affected organs in ratio $14.9 \%$. In a comparative study among 53981 sheep slaughtered in Hail city, about $7.06 \%$ sheep were infected [1].

In other countries around Saudi Arabia, in recent studies in Sudan, discovered that the rate of infection is higher in old animals more than a small one. That refers to the life cycle of the Echinococcus takes a long period in the host and grow slowly. The study was on goats in 7 areas in Sudan, recorded about $1.7 \%$ of goats were infected $[9,10]$.

Among four regions in upper Egypt (Hurghada, Qena, Sohag, Aswan), a study about the distribution of Hydatidosis between ruminants, includes about 4498 animals, resulting about $1.97 \%$ infections of all animals, but record a higher rate in sheep $14.1 \%$, and lowest rate in cattle $0.068 \%$. While in the buffalo there is no any infection [11].

In Tanzania, in a short period (about four months) investigate the prevalence of infection among sheep and goats. Conclusion, the ratio in goats, was $22.2 \%$ and in sheep were $16.6 \%$ [12].

Infection with hydatid cysts in intermediate hosts (like sheep) is generally asymptomatic. Diagnosis occurs by examined after slaughter or dissection the corpse through conventional methods and histological examination for the larval under the microscope to the distinction between this larva and other Cestoda larval. Moreover, there are usually no reliable methods for the diagnosis. The abattoirs play an essential role in collecting data and estimating the prevalence rate of disease.

In this study, we conducted to provide a recent view on the current status of Hydatidosis among slaughter sheep in Makkah through periodic visiting to Alkaakia slaughterhouse three times on week for one year from January 2017 to January 2018.

\section{MATERIALS AND METHODS}

\section{Study design}

Studied animals: A total of 52783 sheep were slaughtered in AlKakkia slaughterhouse where many animals are slaughtered to different customers. The Alkakkia slaughterhouse is located in south of Makkah, Saudi Arabia.
A periodic visit to AlKakkia slaughterhouse was conducted in Makkah, 3 times a week for one year (January 2017 to January 2018), to detect the rate of infection with Hydatidosis among slaughter sheep.

Examination of Slaughtered sheep: After slaughtering the skin of sheep, the outer surfaces of the carcass were examined by visual observation for any infection. And then the abdominal cavity was slotted to see the internal organs for visual inspection and palpation to find any small cyst, as well as make a systematic incision of the infected organs. All that was happening with help of veterinarians in the slaughterhouse following the step by WHO/FAO/UNEP 1984 [13].

And then the number of all slaughtered sheep was recorded, the infection rate was calculated, and the infection organs were detected. The present study was focused on liver and muscles because these organs are the most parts of the sheep which are consumed by humans.

\section{Statistical analysis}

All the data were collected undergo the statistical analysis to detect the rate of infection among slaughtered sheep in one year - Moreover, the relationship between the rate of infection and seasonal changes, also the rate of infection in the complete execution and partial execution. Data were analyzed by using SPSS 22 for Windows ( Statistics, USA), to detect Arithmetic mean, Standard deviation, Student $(\mathrm{t})$ test, and Chi-square $\left(\mathrm{x}^{2}\right)$.

\section{RESULT}

The surveys considered in this study reported that a total of 52783 sheep were slaughtered in Alkakkia slaughterhouse. Of these, 4277 (8.10\%) were found infected with hydatid cysts (Figure 1).

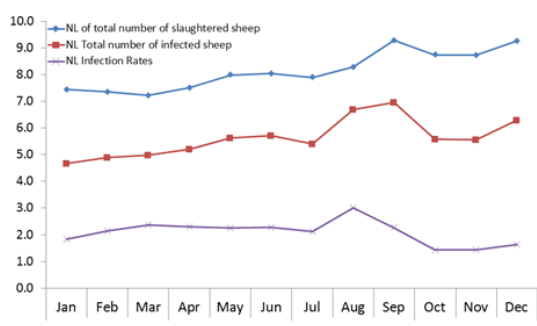

Figure 1: Total rate of infection among slaughtered sheep through one year.

The numbers show the apparent differences in infection rate in this year. The highest rate of infection was in summer the recording rate about $13.62 \%$ of sheep was infected, while the lowest rate was in winter at $5.69 \%$ (Table 1 ).

Table 1: Seasonal prevalence of hydatid cyst in slaughtered sheep in Makkah. 


\begin{tabular}{llll}
\hline Season & Total no. of slaughtered & Total no. of infected & Total rate of infection \\
\hline Spring & 6132 & 607 & $9.89 \%$ \\
\hline Summer & 9722 & 1324 & $13.62 \%$ \\
\hline Fall & 23213 & 1569 & $6.70 \%$ \\
\hline Winter & 13716 & 780 & $5.69 \%$ \\
\hline
\end{tabular}

The relationship between the rate of infection and the infected organs: The most infection organs in sheep were the Liver. The rate of liver infection with Hydatidosis among sheep was 7.55\%. While the rate of muscles infection was lower than the liver, and it records about $0.56 \%$. In case of the infection was in muscles, the sheep will be entirely execution. However, in the case of the liver, it will be partial execution (Table 2).

Table 2: Prevalence of hydatid cyst on one year, according to execution and infected organs among slaughtered sheep.

\begin{tabular}{|c|c|c|c|c|c|}
\hline Month & $\begin{array}{l}\text { Total no. of slaughtered } \\
\text { sheep }\end{array}$ & Complete execution & Rate of infection on muscles & Partial execution & Rate of infection on liver \\
\hline 1 & 1696 & 8 & $0.47 \%$ & 99 & $5.84 \%$ \\
\hline 2 & 1556 & 4 & $0.26 \%$ & 130 & $8.35 \%$ \\
\hline 3 & 1358 & 11 & $0.81 \%$ & 134 & $9.87 \%$ \\
\hline 4 & 1839 & 12 & $0.65 \%$ & 171 & $9.20 \%$ \\
\hline 5 & 2935 & 48 & $1.64 \%$ & 231 & $7.87 \%$ \\
\hline 6 & 3084 & 23 & $0.74 \%$ & 279 & $9.05 \%$ \\
\hline 7 & 2693 & 5 & $0.18 \%$ & 219 & $8.13 \%$ \\
\hline 8 & 3945 & 64 & $1.62 \%$ & 734 & $18.60 \%$ \\
\hline 9 & 10823 & 100 & $0.92 \%$ & 947 & $8.75 \%$ \\
\hline 10 & 6235 & 9 & $0.14 \%$ & 254 & $4.07 \%$ \\
\hline 11 & 6155 & 3 & $0.04 \%$ & 256 & $4.16 \%$ \\
\hline 12 & 10464 & 8 & $0.07 \%$ & 531 & $5.07 \%$ \\
\hline
\end{tabular}

\section{DISCUSSION}

Hydatidosis or cystic Echinococcosis have a worldwide distribution, found almost in every country cause it has a wide variety of hosts, humans, and livestock (especially sheep) record the highest infection rate [14].

Hydatidosis is a common disease in sheep in Saudi Arabia and also in neighboring countries. In this work gives valuable information considering the prevalence of Hydatidosis in slaughtered sheep in Makkah. The prevalence rate of hydatid cyst was $8.10 \%$. This value is almost similar to the prevalence in Hail city, which record $7.06 \%$ [1]. While in other parts of Saudi Arabia record a lower rate of $2.60 \%$ in Al-Madina city and $1.06 \%$ in Riyadh city [6,9]; result in another study indicates a higher rate of infection with Hydatidosis was 69.6\% [15].
Studies were done in neighboring countries recorded different prevalence rate of sheep hydatid cyst in Yamen, Egypt, Sudan, Ethiopia, and Iran was 19.35\%, 14.1\%, 1.7\%, 13.5\%, and $6.45 \%$ respectively $[7,9,11,16,17]$.

The differences in the prevalence of hydatid cyst may arise due to differences in a geographical location, climatic condition, numbers of slaughtered sheep, abundance of the infected definitive host, livestock husbandry, the different sources of sheep in the kingdom, stocking rate, community awareness about the disease, education and economic status of the population, the farming community, and grazing patterns of animals. Importantly, hydatid cyst is a potential threat to humans. Because of the presence of a large stray dog population in the country and improper disposal of abattoir condemned 
organs, there is a big possibility of the disease to effect a higher human population.

Data showed significant seasonal patterns for hydatid cyst in the sheep. The highest condemnation rate is observed in summer and autumn. In a recent study, the highest rate recorded was in winter and spring [8]. While in another study, the highest prevalence of hydatid cyst was in summer [15]. However, this difference refers to the chance of sheep to contact with the final host acquiring the Metacestode regardless time and place proposed.

These differences in rates of infection around the seasons referred to differences in climatic factors, likes temperature, humidity, rainfall, and the nature of grazing.

In our study, we focus on the way of execution, if it is complete or partial and the execution organs. In the partial execution liver was the most infected $(7.55 \%)$ while in the complete execution the muscle record a lower rate of $0.56 \%$. Previous studies demonstrated that liver always is the most infected organs, not only in sheep almost in all livestock [18]. Infection in muscle is rare, the reference to the lifecycle of the parasite [19].

\section{CONCLUSION}

Hydatidosis is a public health risk and causes considerable economic loss. The high infectivity rate of slaughtered sheep with hydatid cyst revealed to the low health awareness among people, and there is no examination of dogs from parasitic diseases, while they were grazing with sheep and transmitted diseases to them. Studies on strain variability must be done it has an essential role in putting new programs for prevention and control of the disease. Periodic epidemiological study Hydatidosis must also be done for nothing the extent of its spread.

\section{REFERENCES}

1. Hasona NA, Amer OH, Morsi A, Raef A. Comparative biochemical, parasitological, and histopathological studies on cystic echinococcosis in infected sheep. Compar Clin Pathol. 2017;26(4):805-810.

2. Moro P, Schantz PM. Echinococcosis: a review. Int J Infect Dis. 2009;13(2):125-33.

3. Cardona GA, Carmena D. A review of the global prevalence, molecular epidemiology, and economics of cystic echinococcosis in production animals. Vet Parasitol. 2013;192(1):10-32.

4. El-Metenawy TM. An Abattoir Survey Of Metacestodes Among Slaughtered Ruminants At Al-Qassevf Area, Saudi Arabia. 1999.
5. Toulah FH, El AS, Alsolami MN. Prevalence of hydatidosis among slaughtered animals in Jeddah, Kingdom of Saudi Arabia. J Egypt Soc Parasitol. 2012;42(3):563-572.

6. Fdaladdin YAJ, Wakid $\mathrm{MH}$, Alsaggaf AI. Comparative epidemiological studies on Echinococcosis of local and imported livestock in Al-Madina Al-munawwarah in Saudi Arabia. Egypt J Hosp Med. 2013;50(1):108-126

7. Fikire Z, Tolosa T, Nigussie Z, Kebede N. Prevalence and characterization of hydatidosis in animals slaughtered at Addis Ababa abattoir, Ethiopia. J. Parasitol. Vector Biol. 2012;4(1):1-6.

8. Almalki E, Al-Quarishy S, Abdel-Baki A-AS. Assessment of the prevalence of hydatidosis in slaughtered Sawakny sheep in Riyadh city, Saudi Arabia. Saudi J Biolog Sci. 2017;24(7):1534-1537.

9. Abdella AMO. Prevalence and risk factors of goats hydatidosis in west darfur state-sudan. SUST Repos. 2017.

10. Mohamadin SA, Abdelgadir AE. Study on hydatid cyst infection in Slaughterhouses in Khartoum state, Sudan. Arch App Sci Res. 2011;3(6): 18-23.

11. Omar M, Sultan K, Haridy M, Omran A. Prevalence of cystic echinococcosis in slaughtered ruminants in different abattoirs, Upper Egypt. American J Animal Vet Sci. 2013;8(3):117-121.

12. Miran M, Kasuku A, Swai E. Prevalence of echinococcosis and Taenia hydatigena cysticercosis in slaughtered small ruminants at the livestock-wildlife interface areas of Ngorongoro, Tanzania. Vet World. 2017;10(4):411.

13. Eckert J, Gemmell M, Matyas Z, Soulsby EJL, World Health Organization. Guidelines for surveillance, prevention and control of Echinococcosis/Hydatidosis. 1984.

14. Eckert J, Gemmell M, Meslin F-X, Pawlowski Z. WHO-OIE manual on Echinococcosis in humans and animals: a public health problem of global concern. World organization for animal health Paris, 2001.

15. Toulah FH, El Shafi AA, Naem M. Hydatidosis among Imported Animals in Jeddah, Saudi Arabia. J Liver Clin Res. 2017;4(1):1031.

16. Al-Shaibani I, Saad FA, Al-Mahdi H. Cystic echinococcosis in humans and animals at Dhamar and Taiz governorates, Yemen. Int J Curr Microbiol App Sci. 2015;4(2):596-609.

17. Basti AA, Rokni N, Hajimohamadi B, Athari S, Misaghi A, Nasrabadi H. Prevalence and intensity study of hydatidosis in slaughtered buffaloes in Urmia City. J Vet Res. 2009;64(3): 249-251.

18. Azlaf R, Dakkak A. Epidemiological study of the cystic echinococcosis in Morocco. Vet Parasitol. 2006;137(1-2):83-93.

19. Tekin R, Avci A, Tekin RC, Gem M, Cevik R. Hydatid cysts in muscles: clinical manifestations, diagnosis, and management of this atypical presentation. Rev Soc Bras Med Trop. 2015;48(5): 594-598. 